\title{
Saúde mental na infância e adolescência
}

\begin{abstract}
É com grande satisfação que apresentamos aos leitores da Revista Brasileira de Psiquiatria o Suplemento de Saúde Mental na Infância e Adolescência. O Brasil tem grande número de crianças e adolescentes que necessitam de atendimento especializado em saúde mental. Porém, ainda é limitado o número de profissionais com formação específica em psiquiatria da infância e adolescência. Portanto, procuramos elaborar um suplemento centrado na clínica psiquiátrica, que tivesse utilidade prática e pudesse contribuir para a formação dos profissionais de saúde mental que atendem crianças e adolescentes.

Com o objetivo de oferecer informações atualizadas e relevantes, tanto na área clínica como em pesquisa, convidamos profissionais de várias regiões do país e do exterior para colaborar conosco, produzindo artigos de atualização nas diferentes áreas em que vêm se destacando.

O Suplemento de Saúde Mental na Infância e Adolescência reúne artigos sobre alguns dos principais transtornos mentais observados em crianças e adolescentes, salientando as especificidades do diagnóstico e do tratamento nessa faixa etária. E, sendo a psiquiatria da infância e adolescência uma especialidade intimamente relacionada a outras áreas da medicina, procuramos incluir artigos sobre interconsulta psiquiátrica na pediatria e morbidade psiquiátrica em crianças com alterações neurológicas. O suplemento também inclui artigos sobre epidemiologia dos transtornos mentais e instrumentos de avaliação e pesquisa, dois campos em pleno desenvolvimento em nosso país e fundamentais para a obtenção de evidências que orientem o planejamento de serviços. Entretanto, temos consciência de que tópicos importantes não puderam ser abordados, do mesmo modo que muitos profissionais de excelente nível científico não puderam se fazer presentes por absoluta limitação de espaço.

Ao final desta publicação, o leitor encontrará uma ficha para o cadastramento dos psiquiatras que atendem crianças e adolescentes em nosso país, elaborada pelo Departamento de Psiquiatria da Infância e Adolescência da Associação Brasileira de Psiquiatria. Essa iniciativa tem o mérito de procurar identificar o número, ainda desconhecido, de profissionais trabalhando com essa faixa etária nos diversos estados brasileiros, para futura correspondência.

Como editoras deste suplemento, agradecemos aos autores dos artigos, à equipe da Revista Brasileira de Psiquiatria e da Publishing Solutions e a todos aqueles que contribuíram para tornar este projeto uma realidade. Sem o esforço e a colaboração de todos, não teríamos alcançado nossos objetivos, que visam, fundamentalmente, o benefício de nossos pacientes.
\end{abstract}

Isabel A. S. Bordin e Heloisa Helena A. Brasil

Editoras 